\title{
Induction of the SOS gene (umuC) by 4-quinolone antibacterial drugs
}

\author{
E. G. M. POWER and I. PHILLIPS
}

Department of Microbiology, United Medical and Dental Schools, St Thomas' Hospital, Lambeth Palace Road, London SE1 TEH

\begin{abstract}
Summary. Induction by the 4-quinolone group of antibacterial drugs of the $u m u C$ gene, the SOS function most involved in error-prone DNA repair (together with $u m u D$ ), was assessed in a strain of Escherichia coli harbouring a umuC::lacZ gene fusion. All 4-quinolones tested induced this $u m u C:: l a c Z$ fusion, with maximum induction at 4-quinolone concentrations close to their minimum inhibitory concentrations for this strain, and the SOS Inducing Potential (SOSIP) was closely related to antibacterial activity. Mitomycin C, a known mutagen, was a slightly better inducer (in terms of SOSIP) than any of the quinolones. In contrast, induction by 4-quinolones of the sfiA (sulA) gene, an SOS function involved in cell division inhibition, was better than induction by mitomycin $\mathrm{C}$ in an $E$. coli strain harbouring an sf $i A:: l a c Z$ gene fusion. The umuC gene fusion was induced at lower concentrations of 4quinolone than was the $s f i A$ gene fusion.
\end{abstract}

\section{Introduction}

The ability of the 4-quinolone antibacterial drugs to induce the SOS response in Escherichia coli is well documented. $^{1-4}$ Investigations have concentrated mainly on the expression of the sulA (sfiA) gene, which codes for a cell division inhibitor. ${ }^{1-3}$ Since SOS processing of DNA is error-prone, ${ }^{5,6}$ it has been suggested that quinolones may be (weakly) mutagenic. ${ }^{1,3,7}$ However, insufficient attention has been paid to the fact that the products of the $u m u D C$ genes are a pre-requisite for SOS-mediated mutagenesis. ${ }^{5,6,8-10}$ Furthermore, according to current theory, some SOS genes such as sul $A$ are repressed less strongly than others such as $u m u D C{ }^{6}$ Therefore, a weak inducing signal will lead to derepression and subsequent expression of sulA but not umuDC. We have tried to establish whether quinolones are capable of producing a sufficiently strong inducing signal to permit expression of the $u m u C$ gene as measured by the synthesis of $\beta$-galactosidase in an $E$. coli strain harbouring a $u m u C:: \operatorname{lac} Z$ gene fusion, ${ }^{11}$ and have compared $u m u C$ induction with that of $s u l A$.

\section{Materials and methods}

\section{Bacterial strains}

Strains used in this study are listed in table I. Strain GW1104 is temperature-sensitive, so all experiments were performed at $30^{\circ} \mathrm{C}$.

\section{Antibacterial agents}

The following quinolones were used in this study: ciprofloxacin (Bayer), sparfloxacin, pefloxacin (Rhone Poulenc), ofloxacin (Hoechst), tosufloxacin (Lederle), difloxacin, temafloxacin (Abbott), fleroxacin (Roche), acrosoxacin, nalidixic acid (Sterling Winthrop) and enoxacin (Warner Lambert). The compounds were initially dissolved in $0.01 \mathrm{~N} \mathrm{NaOH}$ and diluted to the required concentrations in sterile distilled water. Mitomycin C (Sigma) was dissolved and diluted in sterile distilled water.

\section{MIC determinations}

From overnight cultures of the strains, $10-\mu$ l were transferred into $2.5 \mathrm{ml}$ of brain heart infusion (BHI) broth (to give $10^{4}-10^{5} \mathrm{cfu} / \mathrm{ml}$ ) containing appropriate concentrations of the quinolones. The mixtures were incubated for $16 \mathrm{~h}$ at $30^{\circ} \mathrm{C}$ and the tubes were examined for growth. The MIC of each quinolone was taken to be the lowest concentration at which there was no visible growth.

Table I. Bacterial strains used in this study

\begin{tabular}{|c|c|}
\hline Strains & Characteristics \\
\hline $\begin{array}{l}\text { Escherichia } \\
\text { coli K12 } \\
\text { GC4415 }\end{array}$ & $\begin{array}{l}\text { thr leu his pyrD trp:: MuC } C^{+} \text {lac malB galK } \\
\text { rpsL srl-300::Tn10 sfiA::Mudl(Ap lac) }\end{array}$ \\
\hline GW $1104^{8}$ & $\begin{array}{l}\text { his-4 tif-1 sfiA11 lac U169 malE::Tn5 uvr } A^{+} \\
\left.\text {umuC::Mud(Ap lac) (temp }{ }^{s} \text { Amp }^{r} \operatorname{Kan}^{r}\right)\end{array}$ \\
\hline
\end{tabular}




\section{Induction of SOS genes}

Buffers and reagents for SOS induction. B buffer was $\mathrm{Na}_{2} \mathrm{HPO}_{4} 16.1 \mathrm{~g}, \mathrm{NaH}_{2} \mathrm{PO}_{4} . \mathrm{H}_{2} \mathrm{O} 5.5 \mathrm{~g}, \mathrm{KCl} 0.75 \mathrm{~g}$, $\mathrm{MgSO}_{4} .7 \mathrm{H}_{2} \mathrm{O} 0.25 \mathrm{~g}$, sodium dodecyl sulphate (SDS) $1 \mathrm{~g}, \beta$-mercaptoethanol $2.7 \mathrm{ml}$, distilled $\mathrm{H}_{2} \mathrm{O}$ to $1 \mathrm{~L}$, adjusted to $\mathrm{pH}$ 7. ONPG solution $(5 \mathrm{mg} / \mathrm{ml})$ was ONPG $500 \mathrm{mg} / 100 \mathrm{ml}$ in phosphate buffer, $\mathrm{pH} 7$. Phosphate buffer, $\mathrm{pH} 7$ was $0.1 \mathrm{M} \mathrm{Na}_{2} \mathrm{HPO}_{4} \cdot 7 \mathrm{H}_{2} \mathrm{O}$ $61 \mathrm{ml}$ and $0.1 \mathrm{M} \mathrm{NaH}_{2} \mathrm{PO}_{4} \cdot \mathrm{H}_{2} \mathrm{O} 39 \mathrm{ml}$.

The test strains were grown overnight in BHI broth at $30^{\circ} \mathrm{C}$ and $0 \cdot 1-\mathrm{ml}$ volumes were then diluted in $5 \mathrm{ml}$ of BHI broth and incubated at their respective temperatures in a shaking waterbath until the cultures reached a density of $2 \times 10^{8} \mathrm{cfu} / \mathrm{ml}\left(\mathrm{c} .3 \mathrm{~h}\right.$ at $\left.30^{\circ} \mathrm{C}\right)$. At this time, ranges of concentrations of 4-quinolones or mitomycin $\mathrm{C}$ were mixed with the cultures and incubated for $3 \mathrm{~h}$ at $30^{\circ} \mathrm{C}$. The $\beta$-galactosidase activity was then measured.

The assay procedure for $\beta$-galactosidase was similar to that described previously. ${ }^{12}$ Samples $(0.3 \mathrm{ml})$ of the reaction mixtures were added to $2.7 \mathrm{ml}$ of $B$ buffer ${ }^{12}$ and incubated at $37^{\circ} \mathrm{C}$ for $10 \mathrm{~min}$ for the temperature to equilibrate. The $\beta$-galactosidase assay was then initiated by adding $0.6 \mathrm{ml}$ of ONPG solution. The assay was terminated after an appropriate time for colour development (10-90 min) by adding $2 \mathrm{ml}$ of $1 \mathrm{M}$ $\mathrm{Na}_{2} \mathrm{CO}_{3}$ solution. The absorbance at $420 \mathrm{~nm}\left(\mathrm{~A}_{420}\right)$ was read against a colorimeter blank in which the bacterial culture was replaced by BHI broth. Time of colour development was adjusted so that the final $\mathrm{A}_{420}$ was approximately $0 \cdot 1-0 \cdot 4$. Units of enzyme activities were calculated according to the formula used by Miller $:^{13}$ Miller Units of $\beta$-galactosidase activity $=$

$$
1000\left[\frac{A_{420}-\left(1.75 \times A_{550}\right)}{t \times v \times A_{600}}\right]
$$

where, $A_{420}$ and $A_{550}$ were the absorbance values at the relevant wavelength after $t$ min, and $v$ was the reaction volume. $A_{600}$ was the initial absorbance of the culture at $600 \mathrm{~nm}$.

The SOS Inducing Potential (SOSIP) ${ }^{12}$ for each compound is the slope of the linear region of the doseresponse curve. It is a single parameter that represents the number of $\beta$-galactosidase units induced $/ \mu \mathrm{mol}$ of compound tested.

\section{Results}

The induction of the umuC::lacZ fusion by 4quinolones is shown in figs. 1-4. Mitomycin $C$ was included as an example of a known mutagen. All the 4-quinolones tested induced $u m u C$, but differences were evident in the levels of induction and the ranges of concentrations over which the various quinolones induced $u m u C$. These differences are reflected in their SOSIPs (table II). Mitomycin C produced twice as much $\beta$-galactosidase (fig. 4) as the most active quinolone, pefloxacin (fig.3), at their optimum concentrations. The concentration of quinolone at which

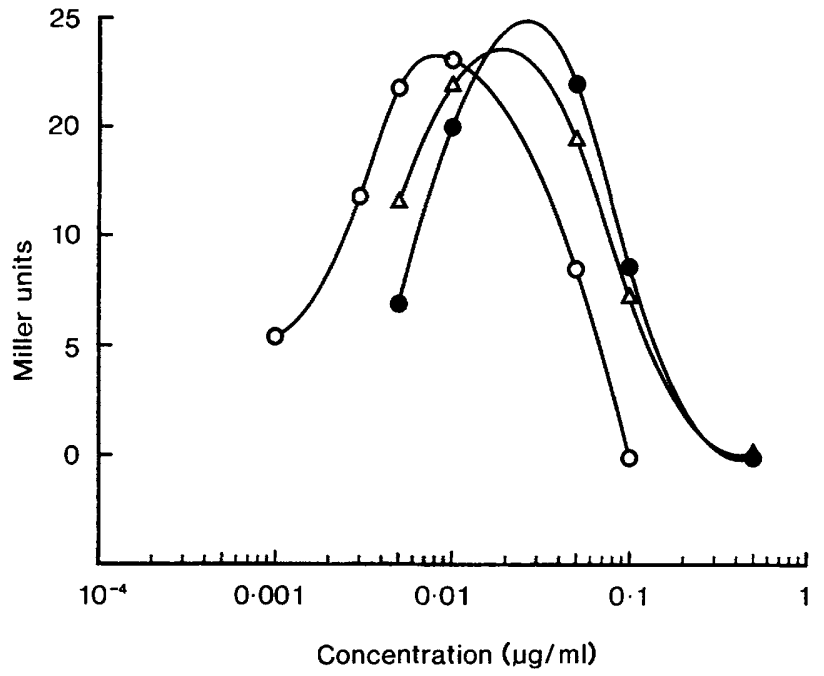

Fig. 1. Induction of $u m u C: \because l a c Z$ by quinolones in $E$. coli strain $\mathrm{GW} 1104$ after $3 \mathrm{~h}$ at $30^{\circ} \mathrm{C}$ : ciprofloxacin $\mathrm{O}-\mathrm{O}$; sparfloxacin $\triangle-\triangle$; tosufloxacin $-\bullet$.

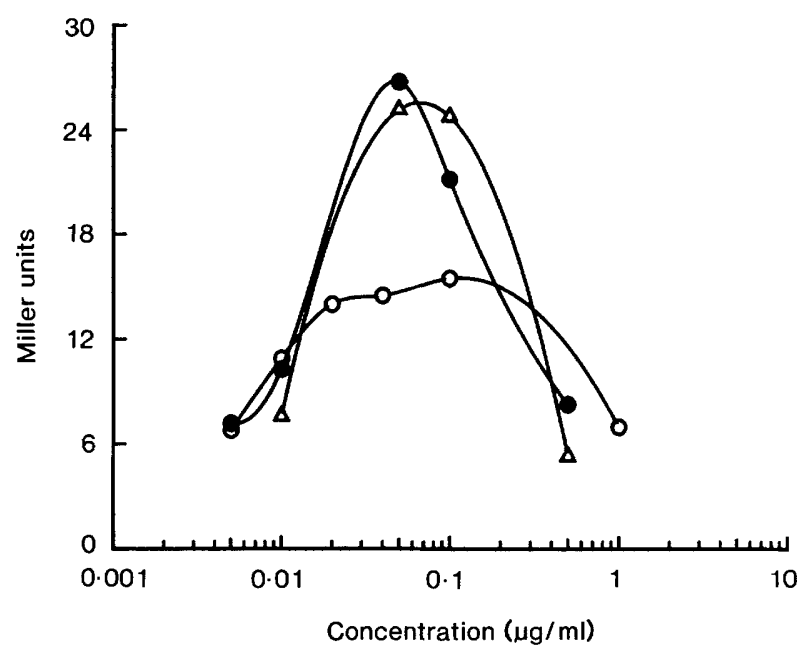

Fig. 2. Induction of $u m u C:: l a c Z$ by quinolones in $E$. coli strain $\mathrm{GW} 1104$ after $3 \mathrm{~h}$ at $30^{\circ} \mathrm{C}$ : ofloxacin $O-O$; norfloxacin $\triangle-\triangle$; temafloxacin - - .

Table II. SOS inducing potential (SOSIP) and maximum inducing concentration for 4-quinolones in $E$. coli strain GW1104 (umuC::lacZ)

\begin{tabular}{|c|c|c|}
\hline 4-Quinolone & $\begin{array}{c}\text { SOSIP } \\
\text { (Miller units } / \mu \mathrm{mol} \text { ) }\end{array}$ & $\begin{array}{l}\text { Maximum inducing } \\
\text { concentration }(\mu \mathrm{M})\end{array}$ \\
\hline Mitomycin $C^{*}$ & $\begin{array}{l}1800 \\
(200)\end{array}$ & 0.599 \\
\hline Ciprofloxacin* & $\begin{array}{c}1600 \\
(5800)\end{array}$ & 0.027 \\
\hline Sparfloxacin & 833 & 0.051 \\
\hline Tosufloxacin & 575 & 0.074 \\
\hline Ofloxacin & 300 & 0.278 \\
\hline Difloxacin & 280 & $0 \cdot 150$ \\
\hline Temafloxacin & 225 & 0.144 \\
\hline Fleroxacin & 143 & 0.136 \\
\hline Norfloxacin & 136 & 0.235 \\
\hline Pefloxacin & 109 & 0.450 \\
\hline Acrosoxacin & 105 & 0.220 \\
\hline Enoxacin & 63 & 0.313 \\
\hline Nalidixic acid & 2 & $7 \cdot 466$ \\
\hline
\end{tabular}

- Values in brackets are SOSIPs measured for sulA in E. coli strain GC4415. 


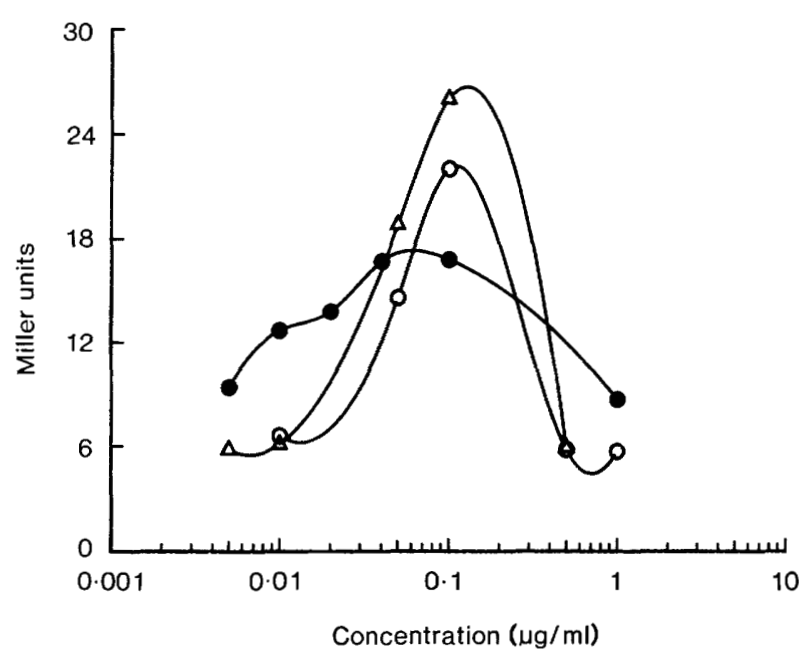

Fig. 3. Induction of $u m u C:: \operatorname{lac} Z$ by quinolones in $E$. coli strain $\mathrm{GW} 1104$ after $3 \mathrm{~h}$ at $30^{\circ} \mathrm{C}$ : enoxacin $\bigcirc-\mathrm{O}$; pefloxacin $\triangle-\triangle$; difloxacin

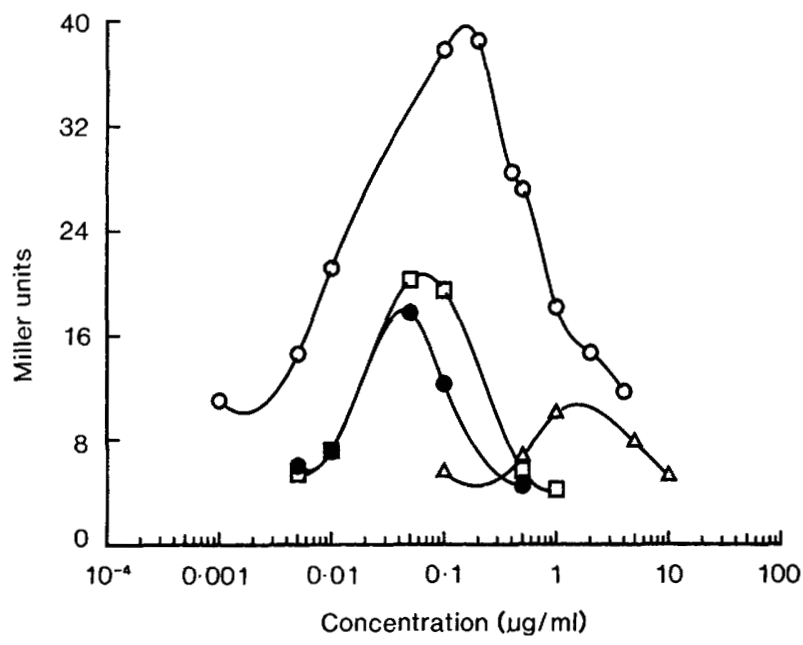

Fig. 4. Induction of $u m u C:: \operatorname{lac} Z$ by quinolones and mitomycin $\mathrm{C}$ in E. coli strain $\mathrm{GWl} 104$ after $3 \mathrm{~h}$ at $30^{\circ} \mathrm{C}$ : mitomycin $\mathrm{C} \mathrm{O}-\mathrm{O}$; nalidixic acid $\triangle-\triangle$; fleroxacin - ; acrosoxacin $\square-\square$.

maximum induction occurred correlated well with, and was close to, the MIC of the respective drug against this strain (GW1104) (fig. 5). The SOSIP of each quinolone correlated even better than the maximum inducing concentration with the respective MIC (fig. 6).

A comparison of the induction of $u m u C$ and $s u l A$ by ciprofloxacin and mitomycin $\mathrm{C}$ is shown in fig. 7. The concentration of ciprofloxacin or mitomycin $\mathrm{C}$ required to induce $u m u C$ was lower than that required to induce $\operatorname{sul} A$; ciprofloxacin induced approximately the same level of sulA as mitomycin C, whereas mitomycin $\mathrm{C}$ induced greater levels of $u m u C$ than ciprofloxacin at their optimum concentrations as measured by the respective lac $Z$ fusions. The level of $s u l A$ induction was at least one order of magnitude higher than the level of $u m u C$ induction. It should be noted also that lower concentrations of ciprofloxacin than of mitomycin $\mathrm{C}$ are capable of inducing sulA whereas both compounds induce $u m u C$ at similar concentrations. This is reflected by the SOSIPs of these compounds for both fusions (table II).

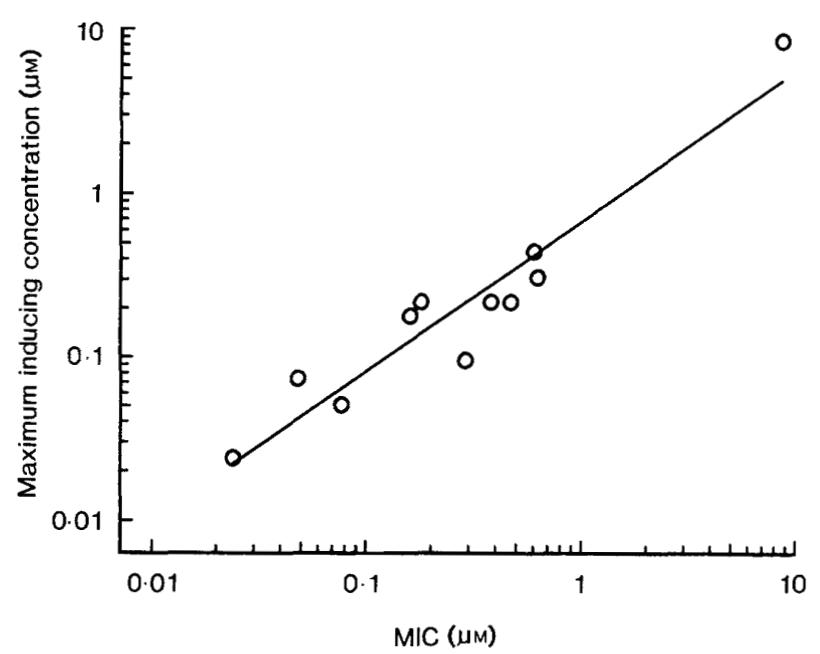

Fig. 5. Correlation between maximum inducing concentration and MIC of quinolones in $E$. coli strain GW1104 (umuC::lacZ); $\mathrm{r}($ correlation coefficient $)=\mathbf{0 . 9 5 4}$.

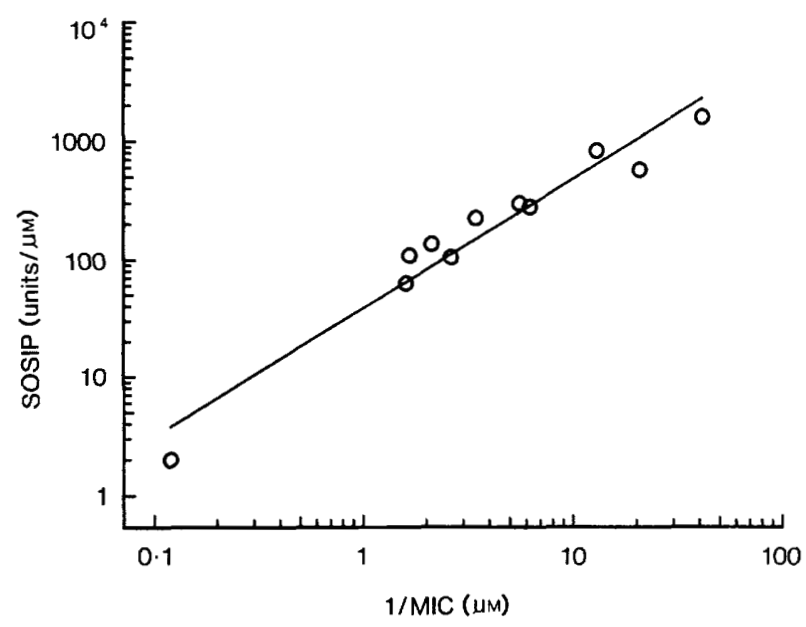

Fig. 6. Correlation between SOS inducing potential and MIC of quinolones in $E$. coli strain GW1104 (umuC::lacZ); r (correlation coefficient $)=0.974$.

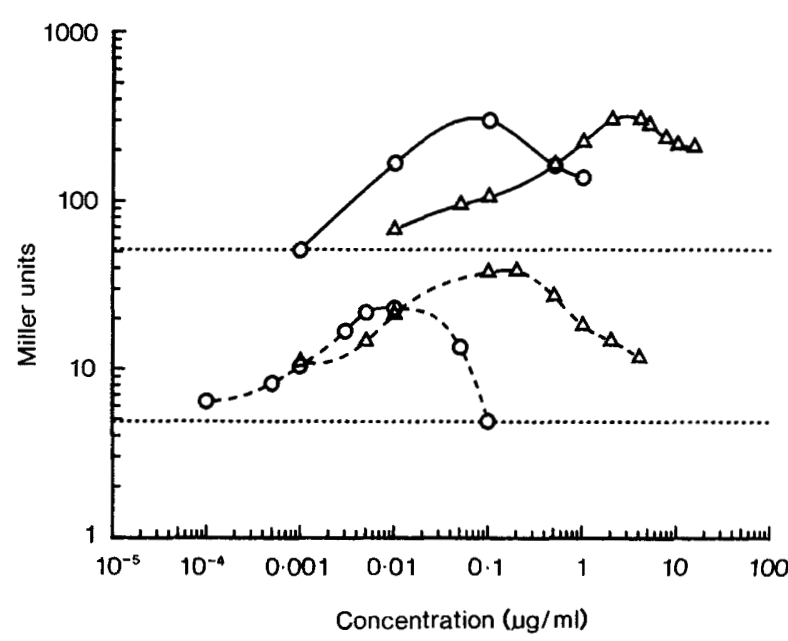

Fig. 7. Comparison of umuC : :lacZ (E. coli GW1104) and sulA : : lacZ $(E$. coli $\mathrm{GC} 4415)$ induction by ciprofloxacin and mitomycin $\mathrm{C}$ after $3 \mathrm{~h}$ at $30^{\circ} \mathrm{C}:-$, sulA ::lacZ induction;---, umuC::lacZ induction; upper dotted line $(\cdots \cdots)$ indicates basal expression of sulA::lacZ, lower dotted line represents basal expression of umu $C:$ : lac Z; ciprofloxacin $\bigcirc$; mitomycin $C \triangle$. 


\section{Discussion}

An $E$. coli sulA fusion strain has been proposed as a screen for potential mutagenicity. ${ }^{12,14,15}$ However, measurement of sulA expression alone will give no indication of the extent of induction of the various SOS genes nor of the mutagenic potential of the inducing treatment. Our results clearly show that the 4-quinolones are capable of inducing the $u m u C$ gene an SOS function involved in error-prone repair and mutagenesis. ${ }^{6,9} \mathrm{UmuD}$ shares a common promotor and operator with $u m u C{ }^{6}{ }^{6}$ hence, induction of the $u m u C$ fusion is effectively also that of $u m u D$. According to current understanding, LexA repressor is strongly bound to the $u m u C$ promotor region and requires a strong SOS inducing signal for derepression and subsequent expression of the gene. ${ }^{6}$ Clearly, 4quinolones are capable of generating such a signal.

Induction of the $u m u C$ gene is probably a better indicator of mutagenic potential than is induction of sulA. This argument is supported by the fact that mitomycin $\mathrm{C}$ exhibits a lower SOSIP than ciprofloxacin with sulA, but a higher SOSIP with umuC (table II). Such a reversal in induction potency has been observed also with ultraviolet light and nalidixic acid. ${ }^{16}$ Nevertheless, problems may arise in the use of the umuC: : lac $Z$ fusion as a screen for mutagenic potential. One disadvantage is that induced levels of $u m u C$ are relatively low (at least in a lac $Z$ fusion) and the fusion may not be sufficiently sensitive to differentiate mutagenic and non-mutagenic compounds accurately.

An interesting paradox is evident on close examination of fig. 7. If $u m u C$ is repressed more strongly than sulA, ${ }^{6}$ low concentrations of ciprofloxacin (or mitomycin C) would be expected to induce sulA but not $u m u C$. However, $u m u C$ is induced at concentrations about 10-fold lower than those which are capable of inducing sulA. This implies that some other mechanism must regulate the expression of these SOS genes, possibly some form of attenuation. Strain differences are unlikely as strains GC4415 and GW1104 are equally sensitive to ciprofloxacin (MIC $0.01 \mathrm{mg} / \mathrm{L}$ ). SulA induction is maximal at quinolone concentrations approximately $10 \times \mathrm{MIC},{ }^{1}$ whereas $u m u C$ induction is maximal at the MIC. The implications of this finding are at present unclear.

The measurement of SOSIP was an attempt to classify the different quinolones in order of potential ability to induce $u m u C$, because interpretation of induction curves was not easy. For example, enoxacin maximally induced $u m u C$ at a lower concentration than pefloxacin, yet pefloxacin induced approximately 2.5 times as much $\beta$-galactosidase (fig. 3). Therefore, it was difficult, if not impossible, to decide which of these parameters was more indicative of relative $u m u C$ inducing ability. The SOSIP takes both factors into account. Previous investigations of SOS induction by assessing expression of $s f i A^{1,3}$ have ranked the 4quinolones in the order of SOS inducing potential ciprofloxacin $>$ fleroxacin $=$ pefloxacin $>$ nalidixic acid. Our SOSIP data (table II) broadly agree with this classification.

The SOSIP for $u m u C$ (table II) may correlate with the potential mutagenicity of the 4-quinolones in bacteria with a functional SOS response, as proposed for sulA. ${ }^{12}$ A previous report on mutagenicity of 4quinolones found that the order was ciprofloxacin $>$ norfloxacin $>$ nalidixic acid. ${ }^{1}$ If SOSIP were to correlate with mutagenicity, sparfloxacin, for example, would be expected to exhibit a stronger mutagenic effect than pefloxacin because it has a higher SOSIP value (table II). Alternatively, SOS-mediated mutagenesis may require only a certain threshold level of $u m u C$ gene product, induction above this threshold resulting in mutagenesis. In this case, all 4-quinolones capable of achieving this level of induction might be expected to be approximately equally mutagenic, assuming that all are capable of mutagenesis only via SOS-processed DNA damage and do not cause other forms of direct DNA damage. It has been suggested by others that it is not valid to predict potential mutagenicity from SOS induction alone. ${ }^{3}$ Preliminary experiments in our laboratory suggest that there is no correlation between SOSIP and mutagenicity at least for 4-quinolones.

We thank K. Hiom for the gift of strain GW 1104 .

\section{References}

1. Phillips 1, Culebras E, Moreno F, Baquero F. Induction of the SOS response by new 4-quinolones. $J$ Antimicrob Chemother 1987; 20: 631-638.

2. Piddock LJV, Wise $R$. Induction of the SOS response in Escherichia coli by 4-quinolone antimicrobial agents. FEMS Microbiol Lett 1987; 41 : 289-294.

3. Thomas A, Tocher J, Edwards DI. Electrochemical characteristics of five quinolone drugs and their effect on DNA damage and repair in Escherichia coli. $J$ Antimicrob Chemother $1990 ; 25: 733-744$.

4. Walters RN, Piddock LJV, Wise R. The effect of mutations in the SOS response on the kinetics of quinolone killing. $J$ Antimicrob Chemother $1989 ; 24$ : 863-873.

5. Little JW, Mount DW. The SOS regulatory system of Escherichia coli. Cell 1982; 29: 11-22.

6. Walker GC. Mutagenesis and inducible responses to deoxyribonucleic acid damage in Escherichia coli. Microbiol Rev 1984; 48: 60-93.

7. Phillips I. Bacterial mutagenicity and the 4-quinolones. $J$ Antimicrob Chemother 1987; 20: 771-773.

8. Bagg A, Kenyon CJ, Walker GC. Inducibility of a gene product required for UV and chemical mutagenesis in Escherichia coli. Proc. Natl Acad Sci USA 1981; 78 : 5749-5753.

9. Elledge SJ, Walker GC. Proteins required for ultraviolet light and chemical mutagenesis. Identification of the products of the umuC locus of Escherichia coli. J Mol Biol 1983; 164: 175-192.

10. Nohmi T, Battista JR, Walker GC. RecA-mediated cleavage 
activities UmuD for UV and chemical mutagenesis. In: Moses RE, Summers WC (eds) DNA replication and mutagenesis. Washington DC, American Society for Microbiology. 1988: 349-354.

11. Huisman O, D'Ari R. An inducible DNA replication-cell division coupling mechanism in $E$. coli. Nature 1981; 290: 797-799.

12. Quillardet $P$, Hofnung $M$. The SOS Chromotest, a colorimetric bacterial assay for genotoxins: procedures. Mutat Res $1985 ; 147$ : 65-78.

13. Miller JH (ed) Experiments in molecular genetics. New York, Cold Spring Harbor Laboratory. 1972.
14. Quillardet P, de Bellecombe C, Hofnung M. The SOS Chromotest, a colorimetric bacterial assay for genotoxins: validation study with 83 compounds. Mutat Res $1985 ; 147$ 79-95.

15. Quillardet P, Huisman O, D'Ari R, Hofnung M. SOS Chromotest, a direct assay of induction of an SOS function in Escherichia coli K-12 to measure genotoxicity. Proc Natl Acad Sci USA 1982; 79 : 5971-5975.

16. Thoms B, Wackernagel W. Regulatory role of recF in the SOS response of Escherichia coli: Impaired induction of SOS genes by UV irradiation and nalidixic acid in a recF mutant. J Bacteriol 1987; 169 : 1731-1736. 